\title{
The Role of Combination Calcipotriol plus Betamethasone Dipropionate Gel in the Treatment of Moderate-to-Severe Scalp Seborrhoeic Dermatitis
}

Felix B. Yap

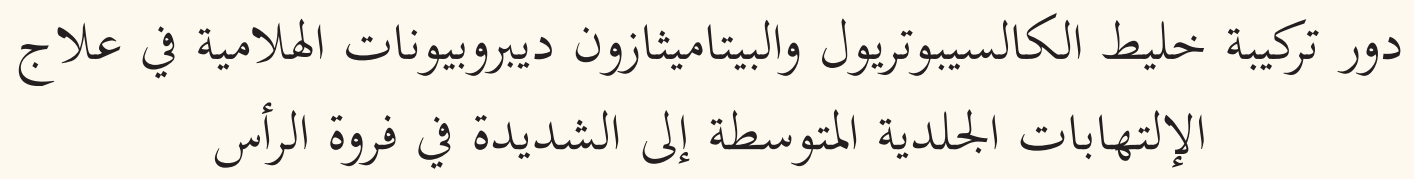

فيليكس بون-بن ياب

ABSTRACT: Objectives: This study aimed to investigate the off-label use of a combination calcipotriol plus betamethasone dipropionate (CBD) gel in the treatment of moderate-to-severe scalp seborrhoeic dermatitis (SSD). Methods: This retrospective study involved 32 patients with SSD who were prescribed CBD gel at the Subang Jaya Medical Centre, Selangor, Malaysia, between January 2016 and December 2017. The Physician Global Assessment Scale was used to assess disease severity. Itching/discomfort was evaluated using a visual analogue scale. Results: The mean age was $35.8 \pm 6.9$ years. Severe disease was seen in $53.1 \%$. Complete clearance was recorded in $15.6 \%, 40.6 \%$ and $59.4 \%$ of patients at weeks two, six and 10 , respectively. By week $10,87.5 \%$ had achieved marked improvement. Both mean itching and discomfort scores significantly improved at weeks two, six and $10(P<0.001)$. Better outcomes were significantly associated with disease duration and itching intensity and discomfort at presentation $(P<0.050)$. Conclusion: CBD gel should be considered as an option for SSD cases not adequately controlled by prior conventional treatment.

Keywords: Seborrheic Dermatitis; Scalp Dermatosis; Betamethasone Dipropionate, Calcipotriol Drug Combination; Off-Label Use; Treatment Effectiveness.

الملخص: الهدف: هدفت هذه الدراسة إلى دراسة الاستخدام الغير مصرح به لهلام مزيج كالسيبوتريول و بيتاميثازون ديبروييونات في

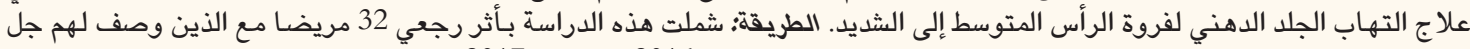

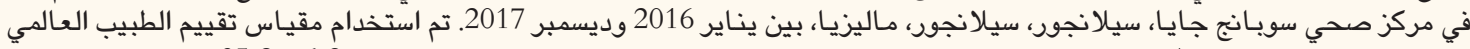

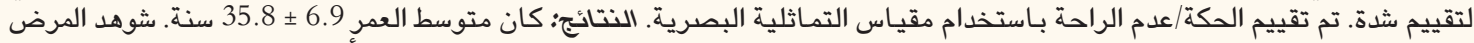

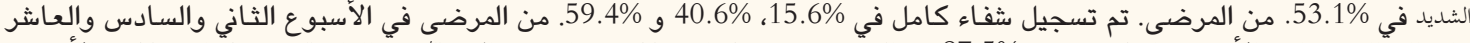

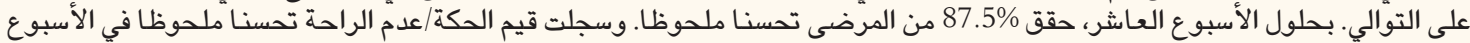

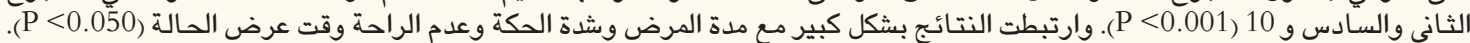

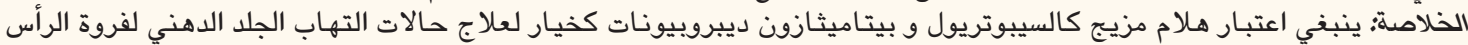
التي يصعبالتحكم بها عن طريق العلاج التقام هنيدي.

الكلمات المفتاحية: التهاب الجلد الدهني؛ التهاب فروة الرأس؛ بيتاميثازون ديبروييونات؛ مزيج كالسيبوتريول الدوائي؛ استخدام بدون تصريح؛ فعالية العلاج.

$\mathrm{T}$ HE MAJORITY OF PATIENTS WITH SCALP SEBORRhoeic dermatitis improve with antifungal, antiinflammatory and keratolytic agents which provide short-term clearance with minimal side-effects, while topical steroids offer better disease control with longer remission periods. ${ }^{1-4}$ However, for those that respond poorly to conventional treatment, other topical offlabel treatments are sometimes applied. One example is a combination of calcipotriol plus betamethasone dipropionate (CBD), an effective topical agent for the treatment of scalp psoriasis in which complete clearance can be seen as early as two weeks. ${ }^{5,6}$
Conventional treatments for seborrhoeic dermatitis are based on the presumed pathogenesis and proliferation of Malassezia furfur and the patient's heightened immunological response. ${ }^{2}$ Based on the assumption that both scalp psoriasis and seborrhoeic dermatitis have an inflammatory component in the disease process, the use of a CBD gel might be beneficial in treatment of the latter condition. ${ }^{7}$ Moreover, this combination reduces the occurrence of side-effects associated with betamethasone dipropionate alone. ${ }^{5}$ This study therefore aimed to investigate the off-label use of a CBD gel in the treatment of moderate-to-severe scalp seborrhoeic dermatitis. 


\section{Methods}

This retrospective study included 32 patients diagnosed with scalp seborrhoeic dermatitis at the Subang Jaya Medical Centre, Selangor, Malaysia, between January 2016 and December 2017. All patients had previously undergone conventional SSD treatment without adequate response. Cases were diagnosed by an attending dermatologist and prescribed twice-weekly doses of $50 \mu \mathrm{g}$ of calcipotriol plus $0.5 \mathrm{mg}$ of betamethasone dipropionate per $\mathrm{g}$ of $\mathrm{Xamiol}^{\circledR}$ gel (Leo Laboratories Ltd., Ballerup, Denmark) until resolution. They were advised to apply the CBD gel to affected areas and to continue using their existing shampoos and taking antihistamines. All of the patients were seen twice weekly until the resolution of their scalp lesions and thereafter monthly for two months.

During each patient visit, the attending dermatologist recorded the severity of the condition using the Physician Global Assessment Scale as either 0 (almost clear), 1 (mild), 2 (moderate), 3 (severe) or 4 (very severe) based on the degree of erythema and scaling and the extent of the skin lesions. ${ }^{8}$ Patients also self-reported symptoms of itchiness and discomfort using a visual analogue scale on a scale of 0 (no symptoms) to 10 (most severe) during each visit.

Response to treatment was graded as either complete clearance, marked improvement ( $>75 \%$ improvement from baseline), moderate improvement (25-75\% improvement from baseline), mild improvement $(<25 \%$ improvement from baseline) and worsening/no improvement. A standardised report form was used to document all sociodemographic, clinical and treatment data recorded during the patient visits. No photographs of the patients' scalps were taken during the course of the study.

Data were analysed using the Statistical Package for the Social Sciences (SPSS), Version 13.0 (IBM Corp., Armonk, New York, USA). Categorical variables were presented as frequencies (percentages), whereas continuous variables were presented as means and standard deviations. Statistical analysis was performed for continuous variables using a Student's t-test. The level of statistical significance was set at $P<0.050$. This study was approved by the local institutional review board of Universiti Tunku Abdul Rahman, Kajang, Selangor, Malaysia.

\section{Results}

The mean age of the patients was $35.8 \pm 6.9$ years and the majority (53.1\%) were female. The mean duration of illness was $12.4 \pm 8.4$ months. Upon initial presentation, $15.6 \%$ of patients had very severe disease, $53.1 \%$ had severe disease and $31.3 \%$ had moderate disease.
Table 1: Characteristics of patients with scalp seborrhoeic dermatitis after 10 weeks of treatment using a calcipotriol plus betamethasone dipropionate gel* $(\mathrm{N}=32)$

\begin{tabular}{|c|c|c|c|}
\hline \multirow[t]{2}{*}{ Variable } & \multicolumn{2}{|c|}{ Mean \pm SD } & \multirow{2}{*}{$\begin{array}{c}P \\
\text { value }\end{array}$} \\
\hline & $\begin{array}{l}\text { Patients with } \\
\text { complete } \\
\text { clearance/ } \\
\text { marked } \\
\text { improvement }^{\dagger} \\
(n=28)\end{array}$ & $\begin{array}{c}\text { Patients with } \\
\text { mild/moderate } \\
\text { improvement }^{+} \\
(\mathrm{n}=4)\end{array}$ & \\
\hline Age in years & $35.2 \pm 7.2$ & $39.8 \pm 2.1$ & 0.224 \\
\hline $\begin{array}{l}\text { Illness } \\
\text { duration in } \\
\text { months }\end{array}$ & $11.5 \pm 7.1$ & $21.0 \pm 11.5$ & 0.032 \\
\hline $\begin{array}{l}\text { Itching } \\
\text { score }^{\ddagger}\end{array}$ & $5.9 \pm 1.2$ & $8.0 \pm 1.2$ & 0.001 \\
\hline $\begin{array}{l}\text { Discomfort } \\
\text { score }^{\ddagger}\end{array}$ & $5.3 \pm 1.0$ & $8.3 \pm 1.0$ & $<0.001$ \\
\hline
\end{tabular}

$S D=$ standard deviation. "Daily Xamiol ${ }^{\circledR}$ gel (Leo Laboratories Ltd., Ballerup, Denmark). ' Assessed by an attending dermatologist using the Physician Global Assessment Scale as either O (almost clear), 1 (mild), 2 (moderate), 3 (severe) or 4 (very severe). ${ }^{8}$ Self-reported by patients using a visual analogue scale on a scale of 0 (no symptoms) to 10 (most severe).

All of the patients had previously demonstrated an unsatisfactory response to treatment with antifungals with or without tar-based shampoos and topical steroids, including desonide, mometasone furoate, betamethasone dipropionate, betamethasone dipropionate plus salicylic acid and clobetasol propionate lotions. Oral antifungals and oral steroids were given to $28.1 \%$ and $6.3 \%$ of patients, respectively. The remaining $65.6 \%$ did not receive oral treatment.

By week two of CBD treatment, 53.1\% and 15.6\% demonstrated marked improvement and complete clearance, respectively. By week six, 40.6\% had achieved complete clearance; this rate improved to $59.4 \%$ by week 10. By week 10, all patients demonstrated at least moderate improvement, with $87.5 \%$ achieving either complete clearance or marked improvement. One patient required oral steroids at week six to control the disease.

Mean itch scores significantly declined from 6.1 at baseline to 2.3, 1.7 and 2.5 at weeks two, six and 10, respectively $(P<0.001)$. Similarly, mean discomfort scores significantly decreased from 5.6 at baseline to $1.8,1.5$ and 2.3 at weeks two, six and 10 , respectively $(P<0.001)$. Patients with marked improvement or total clearance had a significantly shorter disease duration and decreased itching intensity and discomfort at presentation $(P<0.050$ each) [Table 1$]$. No adverse effects or side-effects were reported. The majority of patients $(62.5 \%)$ discontinued CBD treatment after six weeks due to clearance of the lesions and were lost to further follow-up. 


\section{Discussion}

Calcipotriol is a vitamin D analogue licensed for use in the treatment of psoriasis; however, it has been used extensively as an off-label treatment for a variety of other diseases as well. ${ }^{9}$ Although it has previously been studied for the treatment of seborrhoeic dermatitis, it did not prove to be effective. ${ }^{10,11}$ In scalp disease, calcipotriol was found to result in an inferior clearance rate after four weeks compared to a betamethasone valerate solution (67.84\% versus 90.06\%; $P<0.05) .{ }^{10}$ For facial seborrhoeic dermatitis, calcipotriol alone resulted in a $5 \%$ clearance rate at four weeks compared to $40 \%$ in placebo-treated patients $(P<0.05) .^{11}$

Combining calcipotriol and betamethasone dipropionate allows for better efficacy and a reduction in the side-effects associated with both agents alone. ${ }^{5}$ In a randomised controlled trial, Kragballe et al. observed that use of a CBD gel in scalp psoriasis allowed for both rapid clearance (due to betamethasone dipropionate) and a longer remission period (due to calcipotriol). ${ }^{6}$ In the current study, the beneficial effect of the CBD gel was noted as early as two weeks, with more than half of the patients demonstrating marked improvement. At 10 weeks, $87.5 \%$ of patients had marked improvement, with significant reductions in itchiness and discomfort. This result is comparable to those seen in other studies utilising CBD gel for scalp psoriasis with rates of complete/near-total clearance ranging from $68.4-87.5 \% \%^{5,6,12,13}$

The present study found that a CBD gel resulted in the improvement of scalp lesions among patients who did not respond to the prior administration of topical steroids. This might have been due to the steroid vehicle utilised; most patients had previously used betamethasone dipropionate, betamethasone dipropionate plus salicylic acid or clobetasol dipropionate lotions containing isopropyl alcohol. Local irritation and dryness are common adverse effects of such lotions, often contributing to non-compliance and discontinuation of treatment. ${ }^{14}$

Limitations of this study include its retrospective nature, the limited number of patients, the high dropout rate following clearance of the scalp lesions, short duration of follow-up and the lack of photographs to evidence clinical improvement. Ideally, a long-term prospective randomised case-control study is needed for a better comparison of treatment outcomes using CBD gel.

\section{Conclusion}

This study found that a CBD gel may be an effective option in the treatment of moderate-to-severe seborrhoeic dermatitis not adequately controlled by prior conv- entional treatment with antifungals and steroids. As such, it may potentially be recommended in such cases as an alternative to conventional treatment, albeit as an off-label indication.

\section{CONFLICT OF INTEREST}

The author declares no conflicts of interest.

\section{FUNDING}

No funding was received for this study.

\section{References}

1. Kastarinen H, Oksanen T, Okokon EO, Kiviniemi VV, Airola K, Jyrkkä J, et al. Topical anti-inflammatory agents for seborrheic dermatitis of the face or scalp. Cochrane Database Syst Rev 2014; CD009446. https://doi.org/10.1002/14651858.CD009446. pub2.

2. Clark GW, Pope SM, Jaboori KA. Diagnosis and treatment of seborrheic dermatitis. Am Fam Physician 2015; 91:185-90.

3. Milani M, Antonio Di Molfetta S, Gramazio R, Fiorella C, Frisario C, Fuzio E, et al. Efficacy of betamethasone valerate $0.1 \%$ thermophobic foam in seborrhoeic dermatitis of the scalp: An open-label, multicentre, prospective trial on 180 patients. Curr Med Res Opin 2003; 19:342-5. https://doi.org/10.1185/030079 903125001875

4. Ortonne JP, Nikkels AF, Reich K, Ponce Olivera RM, Lee JH, Kerrouche N, et al. Efficacious and safe management of moderate to severe scalp seborrhoeic dermatitis using clobetasol propionate shampoo $0.05 \%$ combined with ketoconazole shampoo 2\%: A randomized, controlled study. Br J Dermatol 2011; 165:171-6. https://doi.org/10.1111/j.1365-2133.2011.10269.x.

5. Saraceno R, Camplone G, D’Agostino M, De Simone C, Di Cesare A, Filosa G, et al. Efficacy and maintenance strategies of twocompound formulation calcipotriol and betamethasone dipropionate gel $\left(\mathrm{Xamiol}^{\circ} \mathrm{gel}\right)$ in the treatment of scalp psoriasis: Results from a study in 885 patients. J Dermatolog Treat 2014; 25:30-3. https://doi.org/10.3109/09546634.2013.800182.

6. Kragballe K, Hoffmann V, Ortonne JP, Tan J, Nordin P, Segaert S. Efficacy and safety of calcipotriol plus betamethasone dipropionate scalp formulation compared with calcipotriol scalp solution in the treatment of scalp psoriasis: A randomized controlled trial. Br J Dermatol 2009; 161:159-66. https://doi.org/10.1 111/j.1365-2133.2009.09116.x.

7. Agozzino M, Berardesca E, Donadio C, Franceschini C, de Felice CM, Cavalloti C, et al. Reflectance confocal microscopy features of seborrheic dermatitis for plaque psoriasis differentiation. Dermatology 2014; 229:215-21. https://doi.org/10.11 $59 / 000363289$

8. Pascoe VL, Enamandram M, Corey KC, Cheng CE, Javorsky EJ, Sung SM, et al. Using the Physician Global Assessment in a clinical setting to measure and track patient outcomes. JAMA Dermatol 2015; 151:375-81. https://doi.org/10.1001/jamaderm atol.2014.3513.

9. Wat H, Dytoc M. Off-label uses of topical vitamin D in dermatology: A systematic review. J Cutan Med Surg 2014; 18:91-108. https://doi.org/10.2310/7750.2013.13109.

10. Basak PY, Ergin S. Comparative effects of calcipotriol and betamethasone 17-valerate solution in the treatment of seborrhoeic dermatitis of the scalp. J Eur Acad Dermatol Venereol 2001; 15:86-8. https://doi.org/10.1046/j.1468-3083.2001.00193-9.x.

11. Berth-Jones J, Adnitt PI. Topical calcipotriol is not effective in facial seborrhoeic dermatitis. J Dermatolog Treat 2001; 12:179. https://doi.org/10.1080/09546630152608339. 
12. van de Kerkhof PC, Hoffmann V, Anstey A, Barnes L, Bolduc C, Reich K, et al. A new scalp formulation of calcipotriol plus betamethasone dipropionate compared with each of its active ingredients in the same vehicle for the treatment of scalp psoriasis: A randomized, double-blind, controlled trial. Br I Dermatol 2009; 160:170-6. https://doi.org/10.1111/j.1365-2133.2008.08927.x.

13. Ma L, Yang Q, Yang H, Wang G, Zheng M, Hao F, et al. Calcipotriol plus betamethasone dipropionate gel compared with calcipotriol scalp solution in the treatment of scalp psoriasis: A randomized, controlled trial investigating efficacy and safety in a Chinese population. Int J Dermatol 2016; 55:106-13. https:// doi.org/10.1111/ijd.12788.
14. Katz HI, Lindholm JS, Weiss JS, Shavin JS, Morman M, Bressinck R, et al. Efficacy and safety of twice-daily augmented betamethasone dipropionate lotion versus clobetasol propionate solution in patients with moderate-to-severe scalp psoriasis. Clin Ther 1995; 17:390-401. https://doi.org/10.1016/0149-2918(95)8 0104-9. 